\title{
An Apparatus for Studying Autoignition of Engine Fuels: Results with Normal Heptane and Normal Hexane
}

\author{
William J. Levedahl and Frank L. Howard
}

\begin{abstract}
A single-cylinder ASTM-CFR fuel-testing engine with a variable compression ratio has been modified to facilitate the study of compression-ignition of homogeneous fuel-air mixtures. An investigation of this type of combustion may lead to a better understanding of engine knock. A cylinder-pressure limiter is described that permits firing a small number of cycles, the first of which is uncontaminated by exhaust gases. Pressure-crank angle oscillograms of the process are shown. The combustion of $n$-heptane and $n$-hexane was found to take place in two distinct stages over a wide range of fuel-air ratios. The pressure at which the first-stage reaction begins is relatively unaffected by the mixture composition throughout the firing range. The second, or firing, stage occurs most readily at fuel-air ratios near stoichiometric, and ionization during firing is highest in this range of mixture compositions. No ionization was observed during the first stage of combustion with either fuel.
\end{abstract}

\section{Introduction}

Many investigators have recognized two major stages in the combustion of hydrocarbons. The first stage is characterized by a relatively slow reaction following an induction period whose duration depends on experimental conditions such as temperature, pressure, fuel-air ratio, presence of additives, and the condition and area of the surface exposed to the mixture. Cold flames, blue luminescence, and relatively small changes in pressure are some of the physical phenomena associated with the first-stage reactions.

From a chemical standpoint the first isolable material from this reaction is peroxidic in character, and hydroperoxides have been identified. The exact mechanism of peroxide formation is unknown, but it is presumed to result first from the formation of short-lived free radicals from the hydrocarbon molecules, which in turn react with oxygen to form peroxides. Decomposition of these hydroperoxides gives rise to new oxygenated free radicals that act as carriers for the propagation of a chain reaction, some of whose intermediate products have been identified as aldehydes, ketones, and acids.

The progress of the first-stage reaction is governed by experimental conditions and by the molecular configuration of the fuel. It is unlikely that it ever reaches a condition of equilibrium in an engine, or even that a concept of equilibrium could be applied to the reaction. Possibly the first-stage reaction influences the second or "firing" stage of combustion by providing certain essential chain carriers. It may be that the second stage will not occur until the first stage has progressed to a certain point.

In a spark-ignition engine, normal combustion is initiated at the spark plug, and a flame front travels through the mixture from this point of origin, compressing the unburned mixture of fuel and air ahead of it. This unburned portion of the charge is frequently called the "end gas." The temperature of the end gas is increased due to adiabatic compression by the burning gases in and behind the flame front and by motion of the piston. This temperature rise, accompanied by increases of pressure and density, sometimes causes first-stage reactions to occur, often followed by a very rapid second-stage reaction, which may cause combustion knock if it takes place with sufficient rapidity. It is thought that investigation of the characteristics of these reactions may prove helpful in obtaining a better understanding of combustion knock.

In 1947-48 Levedahl and Sargent [1] ${ }^{1}$ studied the autoignition characteristics of diethyl ether, $n$-heptane, and other fuels in a single-cylinder CFR ${ }^{2}$ engine in which a well-mixed charge was ignited by compression in the cylinder. Diagrams of this indicated pressure versus crank angle showed very marked and reproducible evidence of a two-stage combustion reaction. Diagrams made at lower compression ratios showed results similar to those obtained by Peletier [2] and Muhlner [3] in that only the first stage occurred. Peletier made a number of runs at compression ratios low enough to preclude firing and measured the extent of the first stage reaction by measuring the temperature of the exhaust gas. Mulner went further with this method, making graphs of the rise of temperature and the torque obtained at many fuel-air ratios and compression ratios with several gasolines, and obtaining some pressure diagrams.

Retailliau, Ricards, and Jones [4] extended this technique by making analyses of the exhaust-gas and other refinements. Pastell [5] carried out experiments with the same general type of apparatus and added a photomultiplier tube to detect the radiation from cool-flames during the (first-stage) reactions. He also measured the energy liberated by these reactions.

A number of single-cycle rapid-compression machines [ 6 to 15 ] have been built for the purpose of studying autoignition. Most productive of these has been the MIT rapid compression machine with which Leary and coworkers [12 to 15] have obtained significant results from measurements of the delay

\footnotetext{
1 Figures in brackets indicate the literature references at the end of this paper. 2 The Motor Fuels Division of the Cooperative Fuel Research Committee developed the CFR engine for knock testing of engine fuels.
} 
time in the ignition of several fuels under many conditions.

In order to extend and augment work previously reported on compression ignition studies, a program has been initiated to determine how the structure of the fuel affects the duration of preflame reactions and the pressure developed by these reactions. It is planned to use several six-carbon hydrocarbons as fuels. These compounds have a variety of structures; paraffins, naphthenes, olefins, and an aromatic being included. This paper describes the apparatus and the methods of operation, and presents the results of preliminary experiments in which $n$-heptane and $n$-hexane were used as fuels.

\section{Apparatus}

Engine. Figure 1 shows the ASTM supercharge method fuel-rating engine [16], modified for the present work, together with the accessory equipment used. A special cylinder was obtained with three holes for $18-\mathrm{mm}$ spark plugs around its circumference and one $7 / 8$-in. hole in the top. The springs beneath the cylinder were removed and the zero setting on the micrometer used to measure the cylinder height was changed 0.3 in. so that compression ratios in excess of 18:1 could be obtained. An alternating-current dynamometer was used to maintain the engine speed at $600,900,1,200$, or 1,800 rpm.

Cooling system. Immediately before entering the

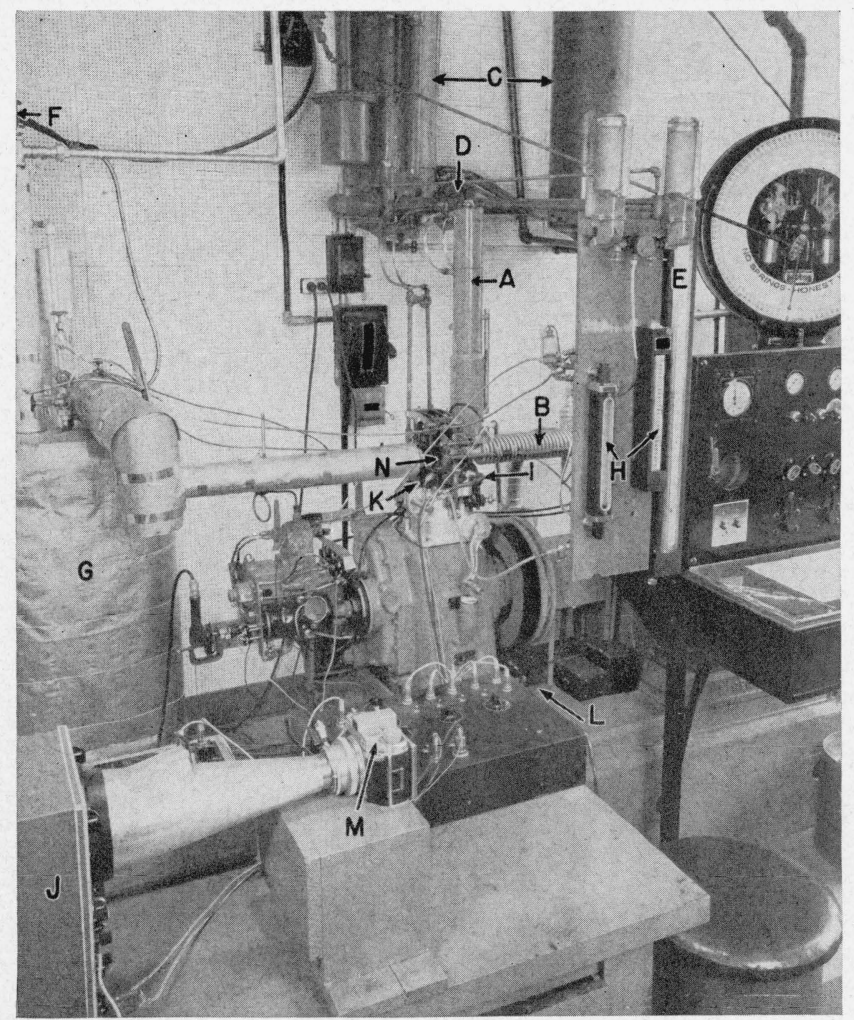

FiguRE 1. Engine and auxiliary equipmeñt. cylinder jacket, the cooling water passed through the central tube of a heat exchanger consisting of $1 / 4$-in. copper tubing within a $5 / 8$-in. tube. Either steam or water could be passed through the annular space. In this way the temperature of the cylinder jacket could be maintained constant at any desired temperature between $150^{\circ}$ and $212^{\circ} \mathrm{F}$ when the engine was in operation under either motoring or firing conditions. A motor-driven vane pump circulated the cooling water through the jacket from a coolant tower (A, fig. 1) used as a reservoir. The exhaust system was cooled by passing water through coils wound on the exhaust pipe, B, and by water sprayed directly into the gases.

Induction system. Air for the mixture was supplied at high pressure, passed through a water trap and was then throttled to 40 psig. A pair of surge tanks, C, and a thermostatically controlled air heater insured a steady flow of air through an ASME sharpedged orifice plate, D. The drop in pressure across the orifice was read directly on a manometer, E, calibrated in pounds of air per hour. Following another throttle valve, which automatically maintained inlet pressure at the desired level, the air passed over a 3,000-w electric heater, F. Fuel was injected into the airstream as it left the heater; vaporization and thorough mixing took place in a large steam-jacketed mixing tank, G. The charge then flowed over a thermometer and through a coppertube flame trap into the engine. The fuel was metered by one of two calibrated flowmeters, $H$, with a combined range of approximately 0.5 to 20 $\mathrm{lb}$ of fuel per hour, and the rate was controlled manually with a needle valve. The composition of the fuel-air mixture is expressed throughout this paper as fraction of stoichiometric fuel, and is given the symbol $\mathrm{S}$ in the figures.

Pressure-measuring equipment. In order to obtain records of the variation of pressure with time during combustion cycles it was necessary to use a sensitive and sturdy pressure pickup with a rapid response and a stable calibration. A Draper-Li strain-gauge unit, I, with an extra-heavy catenary diaphragm and strain-generating tube was selected. A direct-current bridge circuit, of which the pickup formed two legs, and an electronic amplifier fed a voltage that varies linearly with cylinder pressure to an oscilloscope, J, with direct-current amplification on the deflection plates. A resistor in parallel with one leg of the bridge was automatically cut into the circuit once each cycle by a microswitch and caused a calibration mark to be made on the screen at a known pressure. As the indicator operated at a voltage well above ground, a $22 \frac{1}{2}-\mathrm{v}$ battery-potentiometer circuit was used to put a steady opposited bias on the $y$-axis input, and to permit use of the direct-current amplifier on the oscilloscope.

Ionization-detecting equipment. Ionization of the gases in a spark ignition engine has been observed in both knocking and nonknocking combustion $[17,18]$. In order to investigate the relationship between ionization and time in autoignition cycles, a standard 18 -mm spark plug, $\mathrm{K}$, was used as the ionization gap 
in a circuit formed by a $135-\mathrm{v}$ battery and a $250,000-$ ohm resistor. The voltage drop across the resistor. was proportional to the ionization current and was fed to the vertical amplifier of the oscilloscope.

Timing and recording equipment. In order to correlate the pressure-time and ionization-time traces on the oscilloscope with crank angle, it was desirable to have the beam sweep across the face of the tube once each revolution and have the trace marked to indicate known crank positions. These two functions were performed by a photoelectric cell, L, which reacted to a beam of light reflected from fine strips of tinfoil located on the black flywheel so as to register top center, $30^{\circ}, 60^{\circ}$, and $90^{\circ}$ before top center. The strip at $90^{\circ}$ before top center triggered the sweep, and the others produced small vertical marks. The oscilloscope traces were photographed with a camera, M, whose exposure time was set to expose the desired number of consecutive cycles. The shutter was tripped at a selected time in the cycle by a microswitch and solenoid actuated by a projection on the engine camshaft.

Cylinder-pressure limiter. It is often desirable to
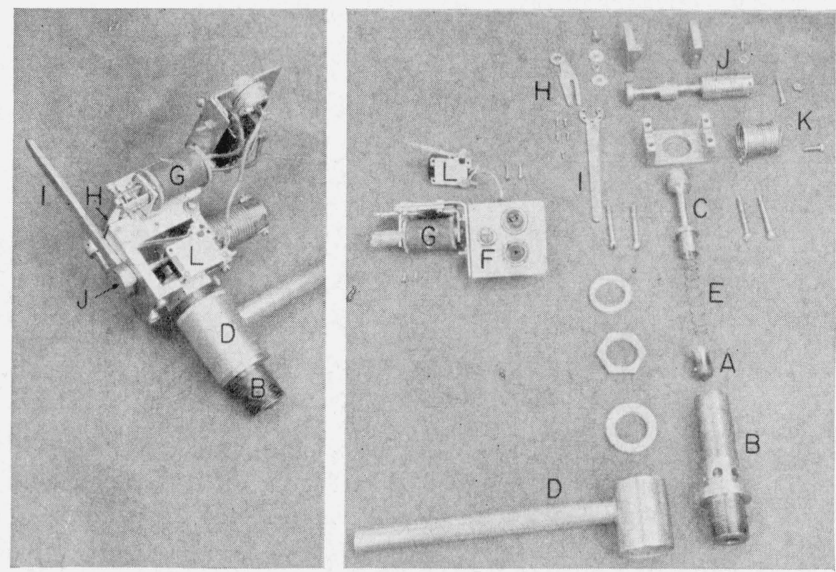

Figure 2. Cylinder-pressure limiter.

record combustion cycles in the absence of residual exhaust gases and hot spots in the combustion chamber. This can be done without disturbing the flow of fuel and air to the engine by keeping the pressure in all except a few chosen cycles from rising enough to cause appreciable chemical reaction. A pressure limiting device was developed for this purpose and mounted in the upper cylinder hole $(\mathrm{N}$, fig. 1). It is shown in assembly and layout in figure 2 .

When the pressure in the cylinder exceeds $10 \mathrm{psig}$, the valve (A, in fig. 2) leaves its seat in the body, B, and moves upward until stopped by the piston, C. The gases in the cylinder can then escape through the annular space between A and B, through holes to the exhaust collector, D, and thence to an exhaust system. On the power stroke, when the pressure again drops below 10 psig, the limiter valve, $\mathrm{A}$, is closed by the spring, E, and remains closed throughout the exhaust and intake strokes, thus permitting the induction of a full charge of combustible mixture.

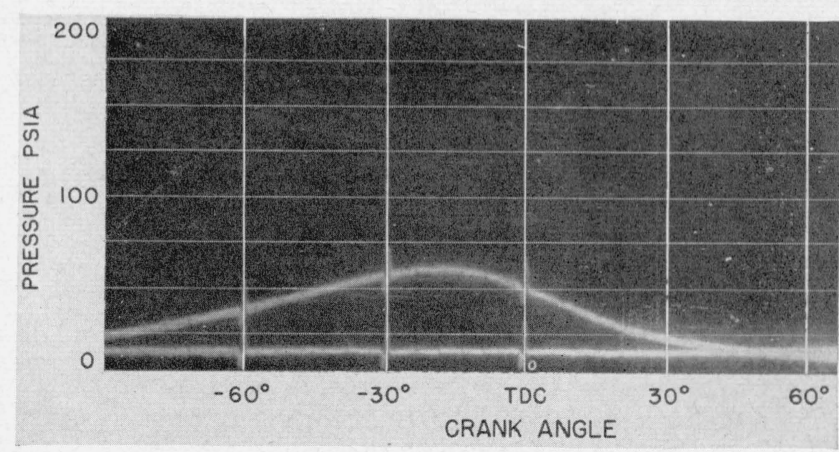

Figure 3. Pressure-crank-angle diagram made with pressure limiter open at a compression ratio of 6.59 .

In this way the mixture can pass through the engine without being burned.

When it is desired to fire the mixture the switch, $\mathrm{F}$, is closed, and at top center on the next exhaust stroke a microswitch actuated by the engine camshaft completes the circuit to the solenoid, $G$, which pulls the trigger, $\mathrm{H}$. The lever, $\mathrm{I}$, which is attached to the camshaft, $\mathrm{J}$, is released, permitting the torsion spring, $\mathrm{K}$, to rotate the cam against the piston, $\mathrm{C}$. After the cam has rotated about $60^{\circ}$ the piston is locked firmly against the valve, $A$, by the cam, permitting the pressure in the cylinder to rise to that of full compression.

When the lever, I, rotates, it operates the microswitch, L, and when bottom center on the inlet stroke is reached another microswitch is closed by the camshaft to complete the circuit to the recording camera. Thus the film is exposed during the first cycle after closing the pressure limiter and for subsequent cycles until the shutter is closed. Figure 3 is a typical pressure record made at $900 \mathrm{rpm}$ with a compression ratio of 6.6 and with the pressure limited in the manner just described. The pressure reached a maximum of about $47 \mathrm{psig}$ at approximately $20^{\circ}$ before top center and dropped off rapidly thereafter.

\section{Experimental Procedure}

Steady firing conditions. The vaporizing tank was preheated by steam, and the engine was motored (driven by the dynamometer) until the inlet air temperature reached the desired value. With the compression ratio set at about $8: 1$, the fuel was introduced at a rate to give mixtures from 0.5 to 0.7 of stoichiometric. Firing usually started immediately; if not, the compression ratio was increased until it did occur. When the rates of flow of the fuel and air and the temperatures had been adjusted to the desired values, the oscilloscope trace of one cycle was photographed.

Cylinder-pressure limiter. The engine was motored at full compression without fuel, and hot water was circulated through the cooling jacket until the temperatures were stabilized. The pressure limiter was placed in operation, the desired flow of fuel was established, and all temperatures were again allowed to stabilize. The exposure time 
of the camera was set to expose three cycles, and | temperature equilibrium is virtually undisturbed the limiter switch, F, was closed. The limiter lever by three firings, series of observations can be made was raised manually after three firings. As the in rapid succession.

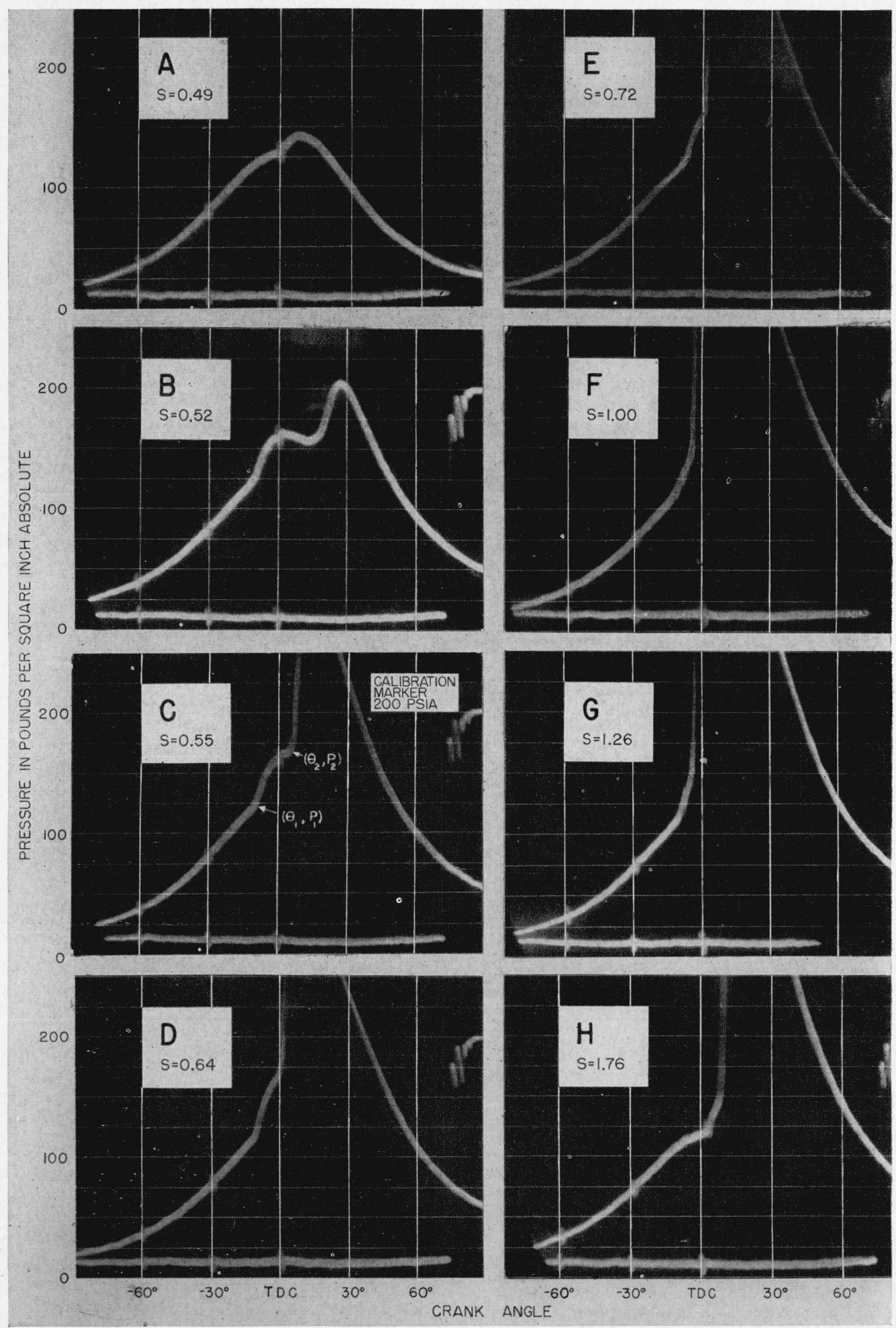

FIGURE 4. Pressure-crank angle diagrams of n-heptane combustion with several mixture compositions at $600 \mathrm{rpm}, 220^{\circ} \mathrm{F}$ inlet temperature, $180^{\circ} \mathrm{F}$ jacket temperature, air consumption $18 \mathrm{lb} / \mathrm{hr}$, and compression ratio 5.68 


\section{Results and Discussion}

\section{Steady Firing of n-Heptane}

Effect of mixture composition. The engine was operated on $n$-heptane over a wide range of mixtures and compression ratios under the following conditions: inlet temperature, $220^{\circ} \mathrm{F}$; jacket temperature, $180^{\circ} \mathrm{F}$; air rate $18 \mathrm{lb} / \mathrm{hr}$; speed, $600 \mathrm{rpm}$. At a compression ratio of $7: 1$, the engine ran steadily at all fuel mixtures between 0.3 and 2.5 times stoichiometric. No knocking was observed with the leanest mixtures, but all those richer than about 0.5 of stoichiometric knocked violently. Decreasing the compression ratio reduced both the knock intensity and the range of fuel-air ratios that would fire. Figure 4 shows one set of typical diagrams of pressure versus crank angle taken at a compression ratio of 5.68 and at various fuel compositions in the range 0.49 to 1.76. The occurrence of two reactions, as indicated by sudden changes in the slope of the pressure curve, are first evident in figure $4, \mathrm{~B}$. The coordinates of pressure and crank angle at which these changes in slope occur are designated by $P_{1}$ and $\theta_{1}$ and by $P_{2}$ and $\theta_{2}$ for the first and second stages, respectively, in figure $4, \mathrm{C}$.

Firing was steady and reproducible from cycle to cycle at all mixture ratios. In figure $4, \mathrm{~A}$, only the first-stage reaction took place. In figure $4, \mathrm{~B}$, the mixture was at the "critically lean" point, that is, a very small decrease in the fuel concentration would prevent the second- or firing-stage of the reaction from occurring. Conversely, a very small increase in fuel would cause steady firing.

Observations of pressure and crank angle made from figure 4 are plotted as functions of mixture composition in figures 5 and 6 , respectively. Figure 5 shows that the pressure, $P_{1}$, necessary to start the first-stage reaction is nearly constant over a wide range of mixtures above the critically lean value of 0.52 . The pressure at which the second stage begins is lowest near stoichiometric and highest for lean mixtures. Figure 6 shows that the time $\theta_{1}$ (in terms of crank angle) at which reaction begins is nearly constant, except for very lean and very rich mix-

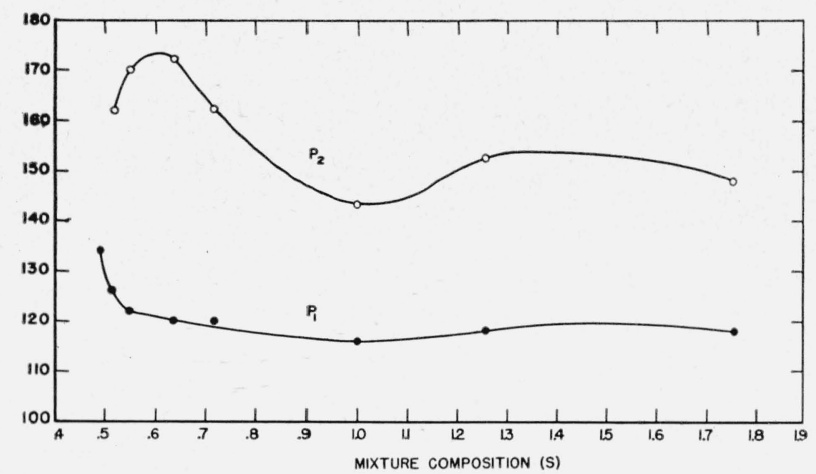

Figure 5. Plot of data from figure 4: Effect of mixture composition on pressures for beginning of first $\left(P_{1}\right)$ and second $\left(P_{2}\right)$ stages of combustion.

Mixture composition is expressed as fraction of stoichiometric fuel.

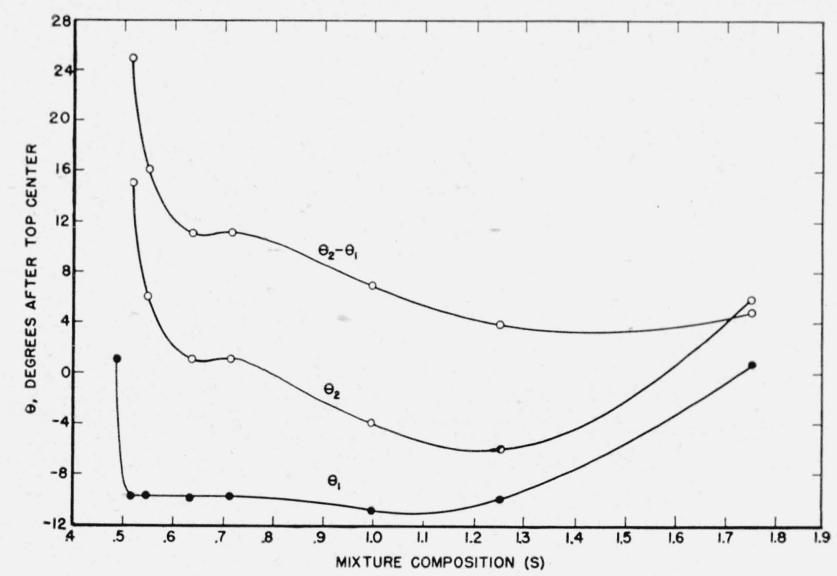

Figure 6. Plot of data from figure 4: Effect of mixture composition on crank angles at which the first stage $\left(\theta_{1}\right)$ and second stage $\left(\theta_{2}\right)$ of combustion begin, and duration of the first-stage reaction $\left(\theta_{2}-\theta_{1}\right)$.

Mixture composition is expressed as fraction of stoichiometric fuel.

tures. It is possible that the reaction starts later in rich mixtures because of their lower specific heat ratio; the temperature and pressure required to start the reaction are not reached until later in the piston stroke. The crank angle at which firing occurs $\left(\theta_{2}\right)$ decreases sharply as the fuel-air ratio is increased in the very lean range, flattens out between about 0.6 and 0.8 stoichiometric then drops more gradually as $S$ is increased. The duration of the first-stage reaction $\left(\theta_{2}-\theta_{1}\right)$ decreases sharply in the lean range, then decreases more gradually as the mixture becomes richer.

\section{Ionization as an Indication of Firing}

Diagrams of ionization versus crank angle. The engine was operated under several combinations of mixtures, engine speed, and inlet temperature to determine the relation between the ionization at one location in the cylinder and the corresponding pressure. In no case was any ionization detected during the first-stage reaction, but a sharp rise in ionization was always noted exactly at the onset of the second stage of combustion. Typical ionization curves for experiments in which $n$-hexane was used are shown in figure 7. Figure 7, A, shows a low wide peak characteristic of lean mixtures, and figure $7, \mathrm{~B}$, shows a curve typical of richer mixtures. Figure 7, C, shows three consecutive cycles, in each of which the sudden rise in ionization current occurred at the same crank angle. The maxima (not shown in this curve) show cycle-to-cycle variations as high as 20 percent. After passing the peak, the traces show considerable oscillation.

Figure 8 shows the effect of mixture composition on peak ionization current, using $n$-hexane as fuel. In every case the compression ratio was set to cause the onset of ionization at exactly top center. When the fuel content of the mixture was increased from 0.5 to 1.1 stoichiometric, the ionization increased about 200 times. Points taken at three engine speeds and two inlet temperatures lie very nearly 
on the same curve, and data taken with $n$-heptane under comparable conditions have shown similar results. From this it would appear that peak ioni-

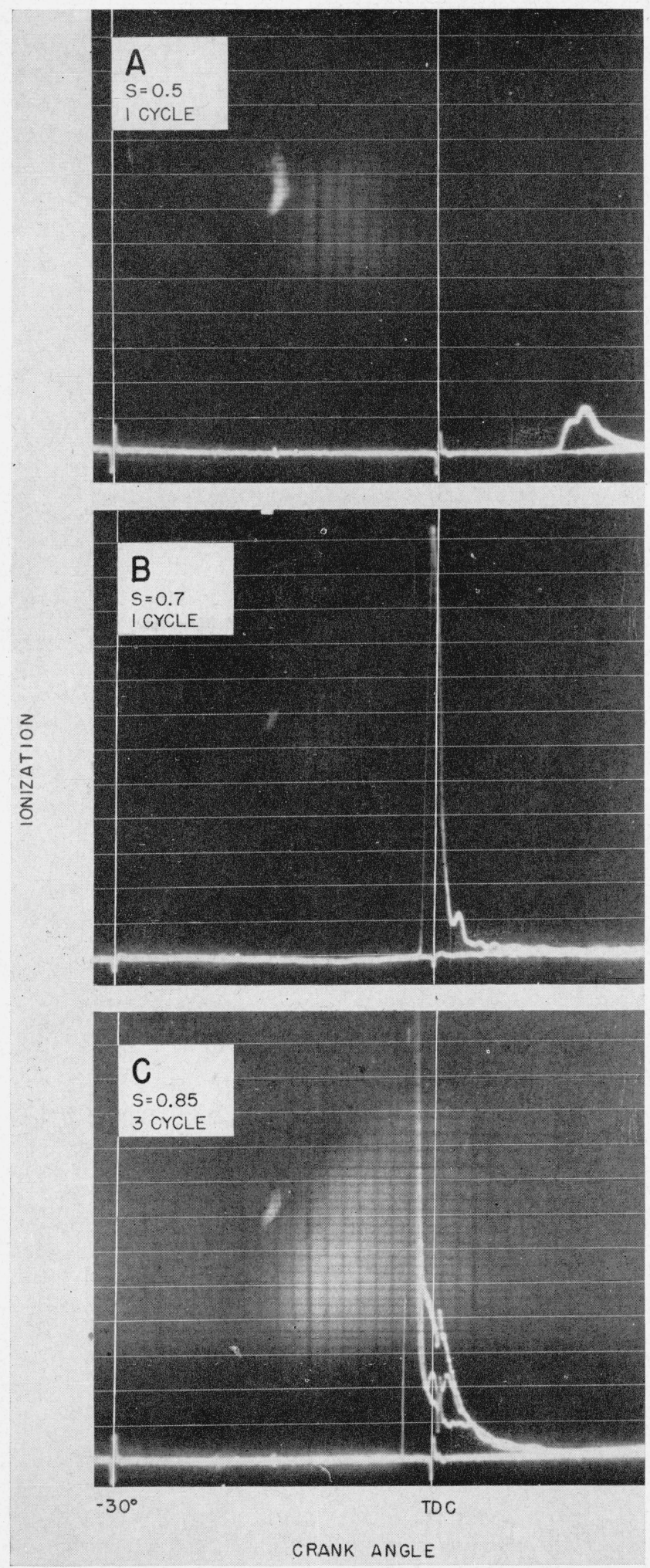

FIgURE 7. Oscillograms of ionization current at three mixture compositions with n-heptane as fuel.

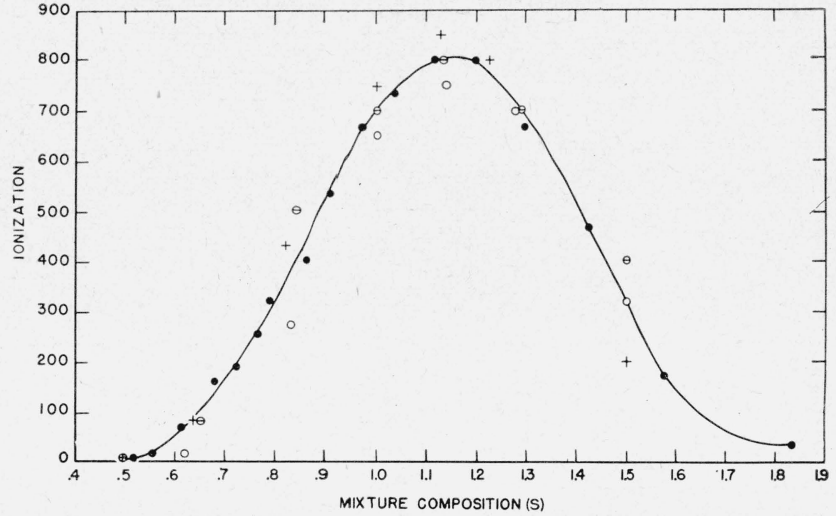

FIGURE 8. Effect of mixture composition on ionization with $n$-hexane as fuel.

The compression ratio was varied to maintain firing at top center. 0,60 ) $\mathrm{rpm}, T$ inlet $=220^{\circ} \mathrm{F} ;-900 \mathrm{rpm}, T$ inlet $=220^{\circ} \mathrm{F} ;+, 1,200 \mathrm{rpm}, T$ inlet $=220^{\circ} \mathrm{F}$; $\Theta, 900 \mathrm{rpm}, T$ inlet $=150^{\circ} \mathrm{F}$. Ionization is expressed as tenths of an inch deflection on the oscilloscope, at full gain. Higher readings were made possible by attenuation. Mixture composition is expressed as fraction of stoichiometric fuel.

zation in autoignition is primarily a function of mixture composition, whereas the changes in other variables cause only secondary effects.

Effect of mixture composition on the compression ratio required to cause firing at top center. The compression ratios used to obtain the points in figure 8 are plotted against mixture composition in figure 9 .

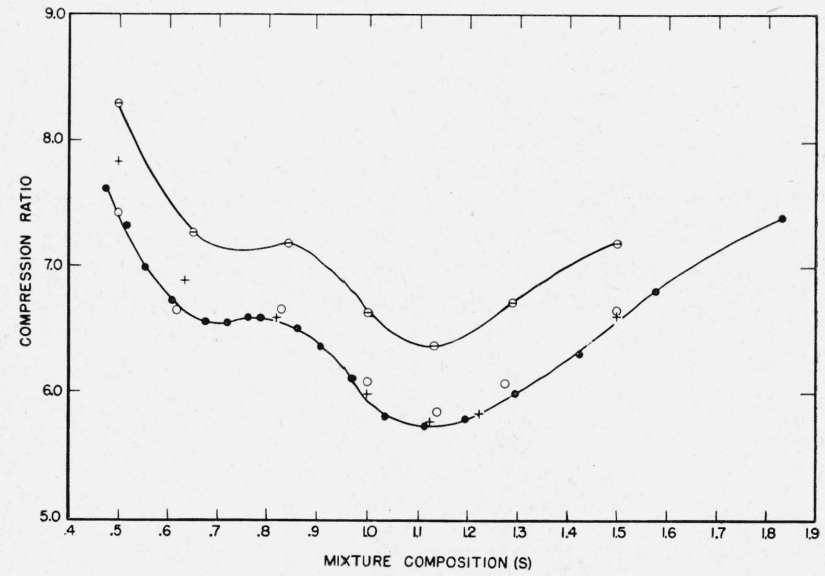

Figure 9. Effect of mixture composition on compression ratio required to maintain continuous firing at top center, with n-hexane as fuel.

, $600 \mathrm{rpm}, T$ inlet $=220^{\circ} \mathrm{F} ; 900 \mathrm{rpm}, T$ inlet $=220^{\circ} \mathrm{F} ;+, 1200 \mathrm{rpm}, T$ inlet $=220^{\circ} \mathrm{F} ;-900 \mathrm{rpm}, T$ inlet $=150^{\circ} \mathrm{F}$. Mixture composition is expressed as frac. tion of stoichiometric fuel.

The effect of engine speed on the required compression ratio is slight, decreased inlet temperature consistently raises the requirement throughout the mixture range. The effects of fuel composition are great, however, with the minimum requirement being at a point slightly richer than stoichiometric. With mixtures between 0.6 and 0.8 stoichiometric there is a reversal of curvature that is comparable to the reversal in the firing angle curve $\left(\theta_{2}\right)$ of $n$-heptane in figure 6 . The reasons for this are not yet understood. 


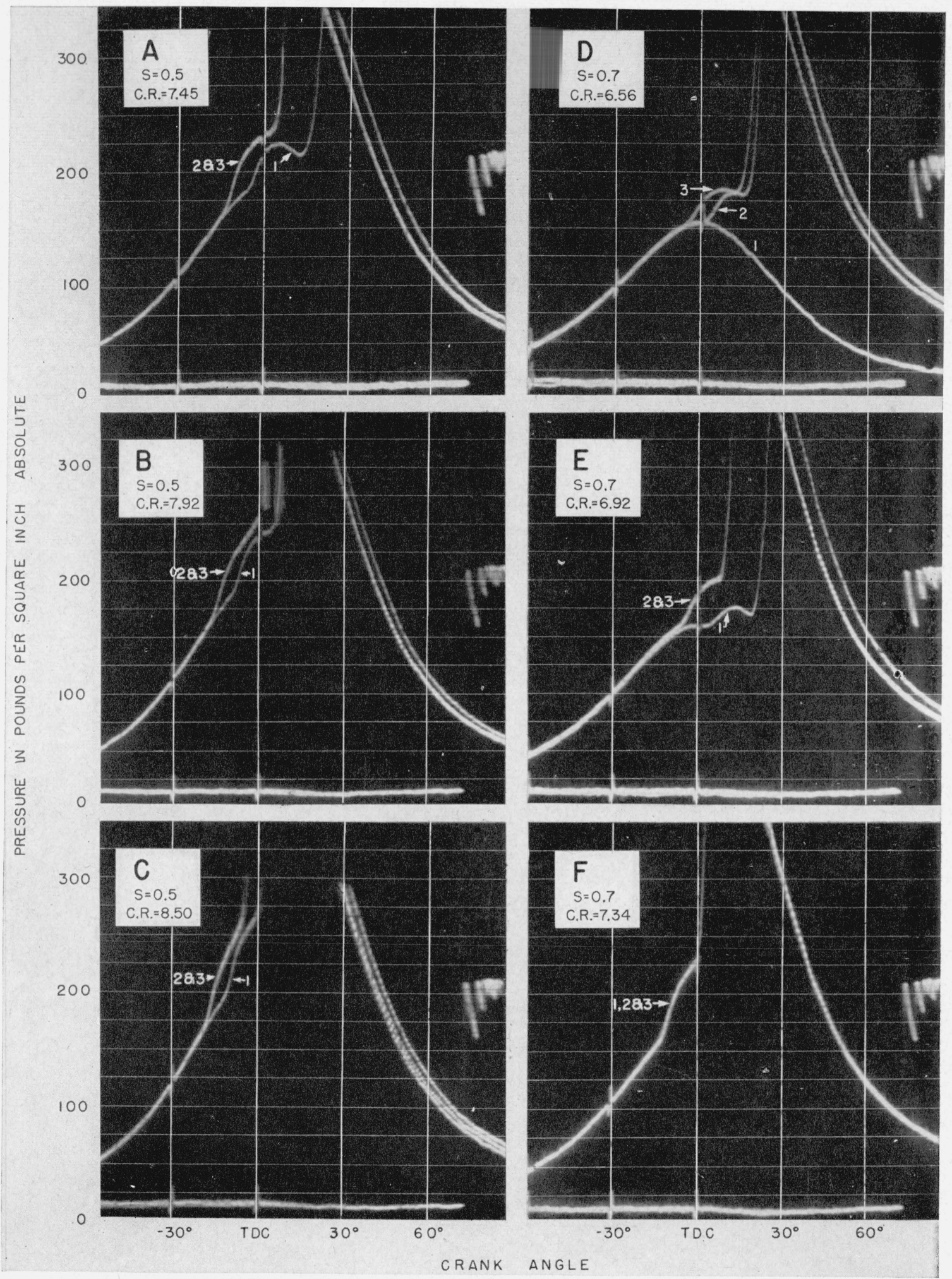

FIgURE 10. Pressure-crank angle oscillograms, showing effect of compression ratio on combustion of n-hexane at two mixture compositions.

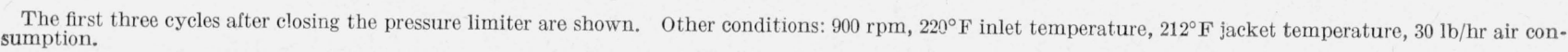




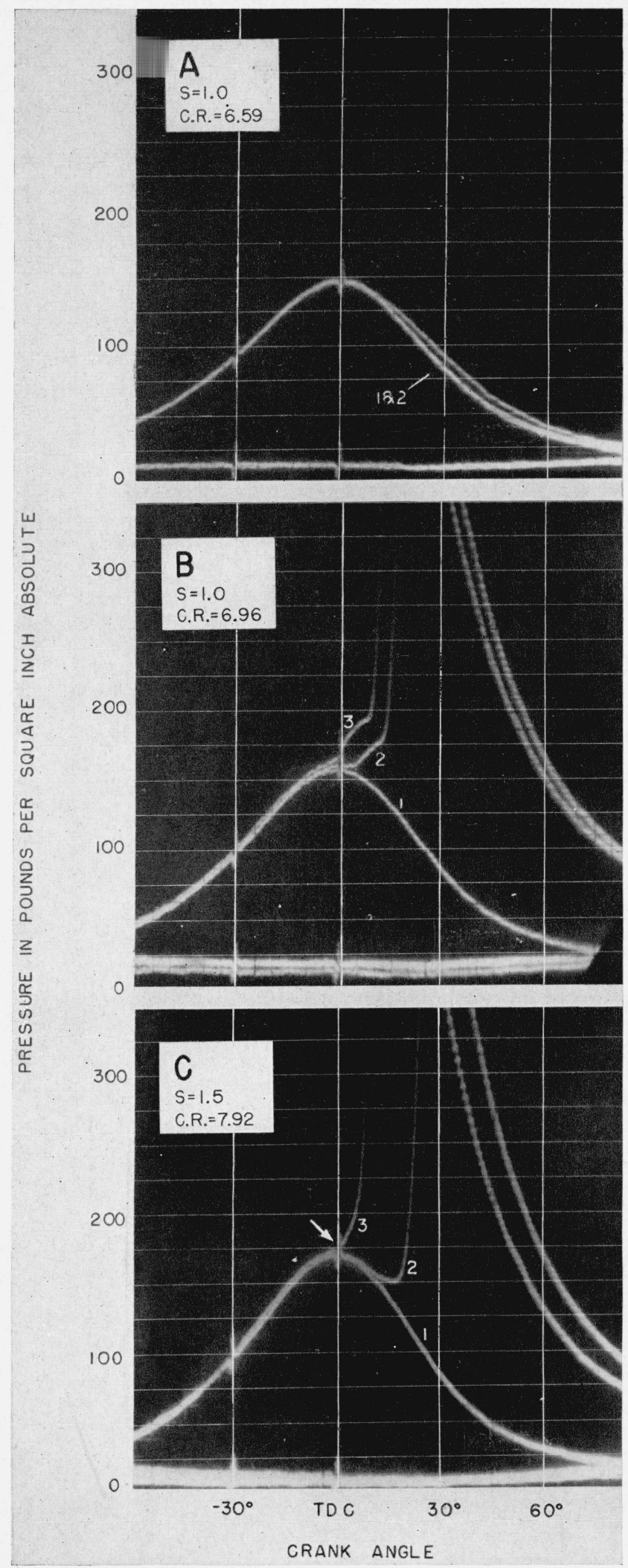

Figure 11. Pressure-crank angle oscillograms at richer mixture.

Continuation of figure 10 .

\section{Experiments with n-hexane with the cylinder pressure limiter}

The cylinder-pressure limiter was installed for the rest of the work with $n$-hexane. Figures 10 and 11 show diagrams of pressure versus crank angle made at $900 \mathrm{rpm}, 212^{\circ} \mathrm{F}$ jacket temperature, $220^{\circ} \mathrm{F}$ inlet temperature, and $30-\mathrm{lb} / \mathrm{hr}$ air consumption. At each mixture the first set of observations was made at the compression ratio that caused firing at top center under steady-firing conditions (see fig. 9). Subsequent observations were made at progressively higher compression ratios, and each was repeated to determine reproducibility. Average differences amounted to less than $1^{\circ}$ of crank angle and 1 psi for $\theta_{1}$ and $P_{1}$, respectively. An accurate determination of the pressure at which firing begins is difficult because the slope of the curve at that point is steep enough to cause considerable reading error.

The oscillograms in figure $10(\mathrm{~A}, \mathrm{~B}$, and $\mathrm{C})$ were made at progressively increased compression ratios with a mixture of 0.5 stoichiometric. The superposed pressure curves of the second and third cycles show earlier firing than in the first cycle at all three compression ratios. This fact seems to indicate that residual exhaust gases from one cycle had an accelerating effect on combustion in the next cycle. At a richer mixture the first cycle in figure $10, \mathrm{D}$, showed no perceptible reaction, but the second and third cycles fired. At higher compression ratios (fig. 10, E, and F) all three cycles fired.

Figure 11, A, shows a slight first-stage reaction beginning at about $10^{\circ}$ after top center on the third cycle with a stoichiometric mixture. Several cycles later (not shown in the figure) the engine began to fire. When the compression ratio was raised (fig. $11, \mathrm{~B})$, no firing occurred on the first cycle, but the second and third cycles fired progressively earlier. It appears that the residual gases from a motored cycle may have an accelerating effect on the reactions in the next cycle even though no perceptible reaction took place in the first.

With a very rich mixture, 1.5 times stoichiometric, figure $11, \mathrm{C}$, shows that firing began very late on the second cycle and near top center on the third. Only a slight evidence of a first-stage reaction is apparent; in the third cycle it appears as a fillet (shown by arrow) between the compression and firing parts of the pressure trace.

The pressure rise due to first-stage reactions decreases as the mixture becomes richer; with the leaner mixtures it is apparently necessary for the first stage to progress farther before the second stage can begin. At the higher fuel concentration it was necessary to use much higher compression ratios to cause firing when the engine is being motored than those shown in figure 9 for steady firing conditions. This phenomenon may be attributed to the large difference between the temperatures in a motoring and a heavily knocking engine. 


\section{Conclusions}

1. $n$-heptane and $n$-hexane both evidence a pronounced two-stage autoignition reaction over a wide range of operating conditions.

2. When all other conditions are held constant, the pressure and crank angle at which the first-stage reaction begins in a steadily firing engine are nearly constant over a range of mixture compositions from critically lean to 1.2 times stoichiometric.

3. The duration of the first stage of the reaction decreases as the mixture is made richer up to about 1.2 stoichiometric, then remains nearly constant.

4. Considerable ionization occurs in the cylinder during firing, but none was observed during the firststage reaction. The ion concentration is affected greatly by fuel-air ratio and is relatively unaffected by changing other operating variables.

5. When residual gases from either a first- or second-stage combustion are in the cylinder, the charge will burn earlier than when uncontaminated.

The authors are grateful to E. F. Fiock, Chief of the Combustion Section, for his advice and assistance in preparing the manuscript of this report.

\section{References}

[1] W. J. Levedahl and G. W. Sargent, Jr., Auto-ignition in an internal combustion engine, Thesis, B. S., Mech. Eng., MIT (1948).

[2] L. A. Peletier, S. G. van Hoogstraten, I. Smittenberg, and L. P. Kooymann, Reactions chemique prealables dans un moteur a essence, Chaleur et Industrie 20, $120(1939)$.

[3] E. Muhlner, Researches on preliminary chemical reactions in spark-ignition engines, NACA Tech. Note 1049 (June 1943).

[4] E. R. Ratailliau, H. A. Ricards, Jr., and M. C. K. Jones, Precombustion reactions in the spark ignition engine, SAE Quarterly Trans. (July 1950).
[5] D. L. Pastell, Precombustion reactions in a motored engine, Preprint of paper presented at SAE Summer Meeting (1950).

[6] H. T. Tizard and D. R. Pye, Experiments on the ignition of gases by sudden compression, Phil. Mag. 44, 79, 121 (July 1922).

[7] H. T. Tizard and D. R. Pye, Ignition of gases by sudden compression, Phil. Mag. 1, 1094 (May 1926).

[8] W. Jost, Reactions of adiabatically compressed hydrocarbon-air mixtures. Third Symposium on Combustion, Flame and Explosion Phenomena, p. 424 to 432 (Williams \& Wilkins Co., Baltimore, Md., 1949).

[9] von H. Teichmann, Reaktionskinetische untersuchungen zum klopfvorgang. II., Z. Elektrochem 47, No. 4, 297 (April 1941).

[10] W. Jost, Explosion and combustion processes in gases (Julius Springer, Berlin, 1939).

[11] F. A. F. Schmidt, Bericht uber die grundsatzlichen forschungsarbeiten uber den zundvorgang, Schriften der Deutschen Akademie der Luftfahrtforschung 54, 77 (1942).

[12] W. A. Leary, E. S. Taylor, C. F. Taylor, and J. U. Jovellanos, A rapid compression machine suitable for studying short ignition delays, NACA Tech. Note 1332 (Feb. 1948).

[13] W. A. Leary, E. S. Taylor, C. F. Taylor, and J. U. Jovellanos, The effect of fuel composition, compression pressure, and fuel-air ratio on the compression-ignition characteristics of several fuels, NACA Tech. Note 1470 (March 1948).

[14] J. U. Jovellanos, E. S. Taylor, C. F. Taylor, and W. A. Leary, An investigation of the effect of tetraethyl lead and ethyl nitrate on the auto-ignition characteristics of iso-octane and triptane, to be published by NACA.

[15] C. F. Taylor, E. S. Taylor, J. C. Livengood, W. A. Rusell, and W. A. Leary, The ignition of fuels by rapid compression, SAE Quarterly Trans. (April 1950).

[16] ASTM Manual of engine test methods for rating fuels (American Society for Testing Materials, Philadelphia, Pa., March 1948).

[17] Charles E. Hastings, Ionization in the knock zone of an internal combustion engine, NACA Tech. Note 774 (Sept. 1940).

[18] R. Vicknievsky, Trans. Faraday Soc. XLII, No. 268, 322 (March-Äpril 1946).

Washington, October 2, 1950. 